\title{
Microwave-Assisted and Metal-Induced
}

\section{Crystallization: A Rapid, and Low Temperature}

\section{Combination}

Paul M. P. Danty,,$^{a, \neq}$ Antoine Mazel,, a, Benoit Cormary, ${ }^{a,},,+$ Maria L. De Marco, Joachim

Allouche, ${ }^{b}$ Delphine Flahaut, ${ }^{b}$ Javier Jimenez-Lamana, ${ }^{b}$ Sabrina Lacomme, ${ }^{c}$ Marie-

Hélène Delville, ${ }^{a^{*}}$ Glenna L. Drisko ${ }^{a,{ }^{*}}$ 

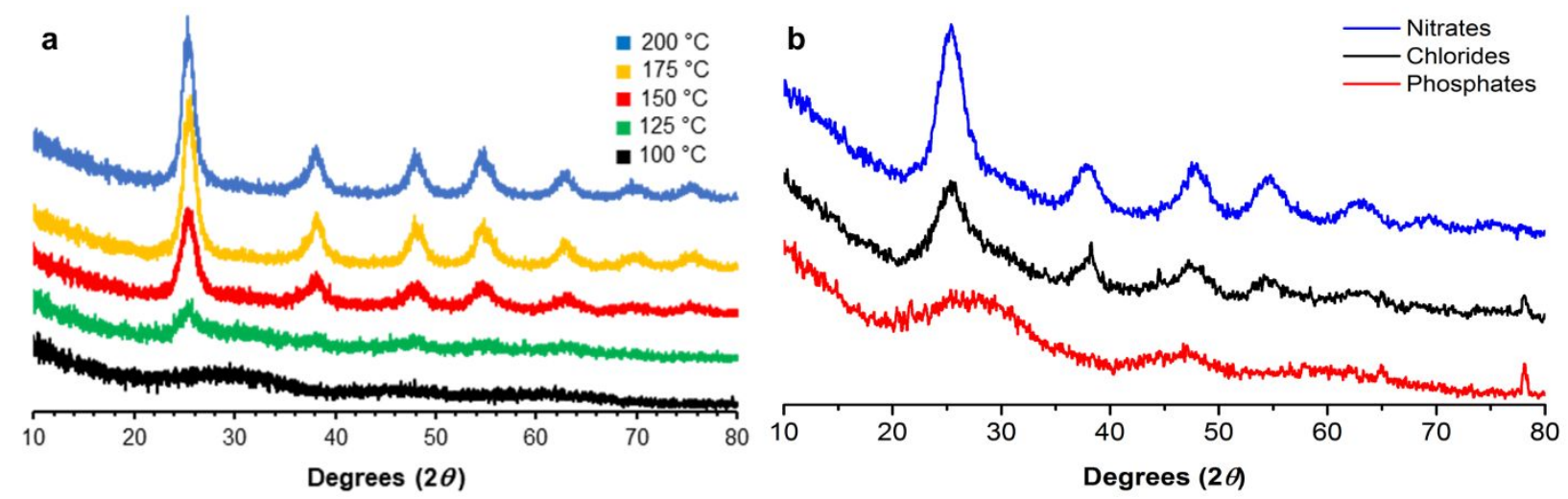

Figure S1. (a) Diffractograms showing the impact of temperature on the crystallinity of $\mathrm{TiO}_{2}$. The samples were treated in the microwave for $45 \mathrm{~min}$ in the presence of a solution of $0.09 \mathrm{M} \mathrm{MnCl}_{2}$. (b) Diffractograms showing the impact of counter ions on crystallization. The samples were treated at $120^{\circ} \mathrm{C}$ in the microwave for $45 \mathrm{~min}$ in the presence of a solution of $0.09 \mathrm{M} \mathrm{Al}^{3+}$ salt, where the counter ion was either a phosphate, a nitrate or a chloride. The solution was composed of water, rather than a mixture of water and ethanol, as was reported for all other samples appearing in this article.
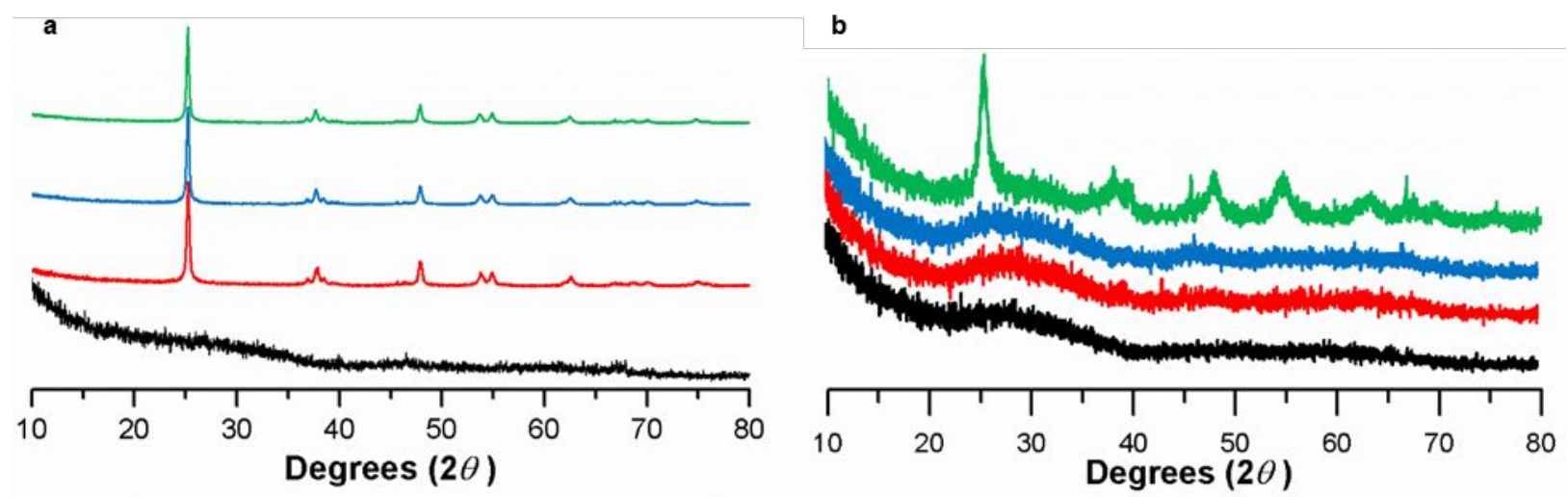

Figure S2. In situ X-ray diffraction of the spheres using convection heating (a) with and (b) without impregnation with $0.09 \mathrm{M} \mathrm{MnCl}_{2}$ at 25 (black), 375 (red), 425 (blue) and 475 (green) ${ }^{\circ} \mathrm{C}$. The peaks correspond to anatase titania (JCPDS 21-1272). 


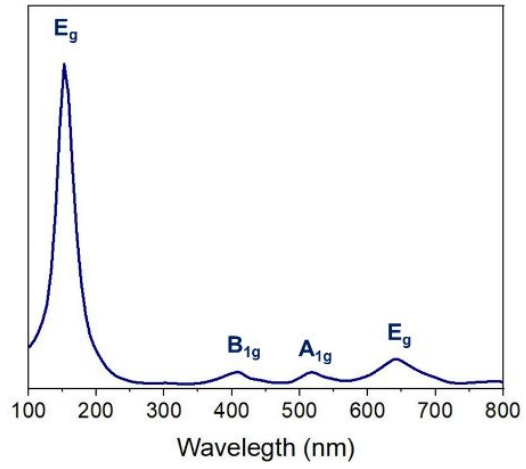

Figure S3. Raman spectroscopy of the spheres crystallized with $0.09 \mathrm{M} \mathrm{MnCl}_{2}$ at $150{ }^{\circ} \mathrm{C}$ for $10 \mathrm{~min}$. The peaks correspond to anatase titania, as indexed in reference 25. 

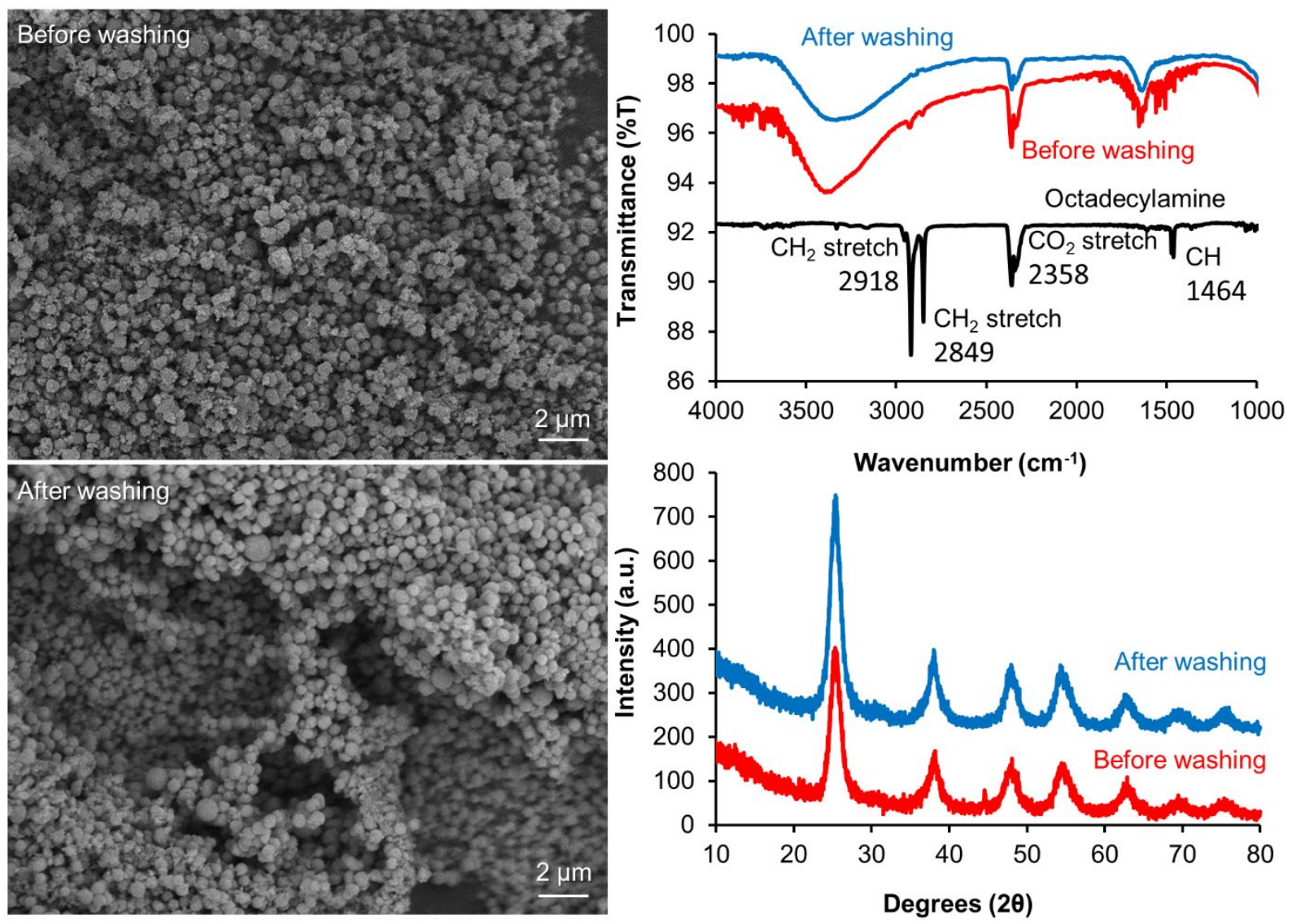

Figure S4. Infrared spectroscopy of the spheres crystallized before (blue) and after refluxing (red) and the spectrum of octadecyl amine (black). The peaks correspond to anatase titania (JCPDS 21-1272). 


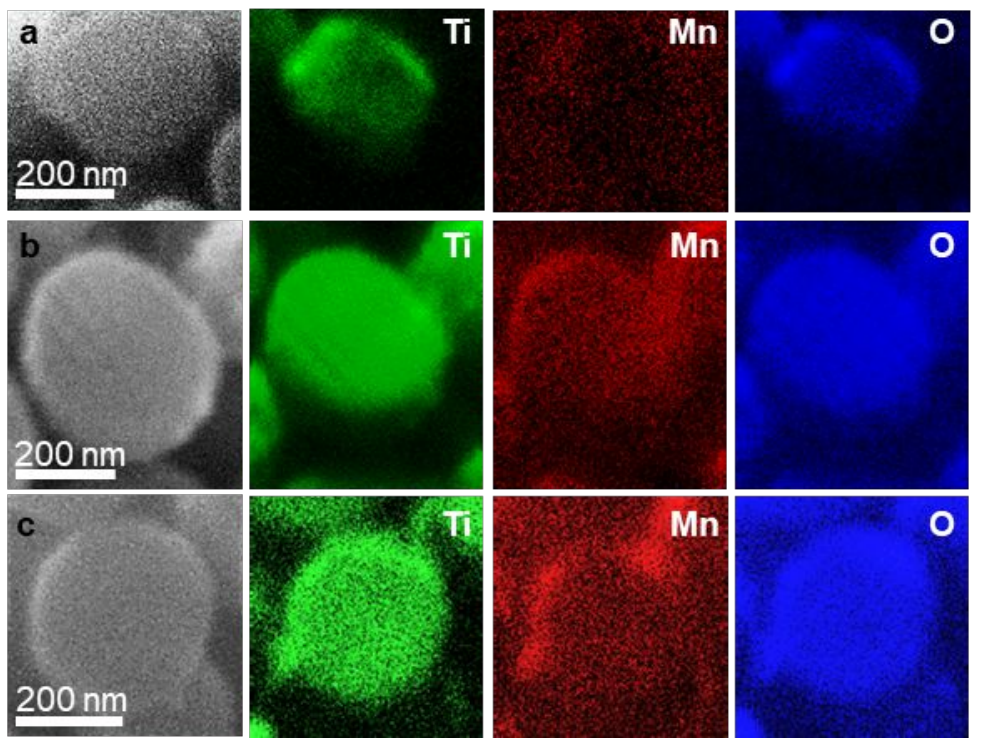

Figure S5. Single crosscut sphere SEM images and corresponding Auger electron spectroscopy mapping of titanium (green), manganese (red) and oxygen (blue) for (a) 5 , (b) 10 and (c) 90 min of microwave radiation time at $150{ }^{\circ} \mathrm{C}$ in contact with a $0.09 \mathrm{M} \mathrm{MnCl}_{2}$ solution. 


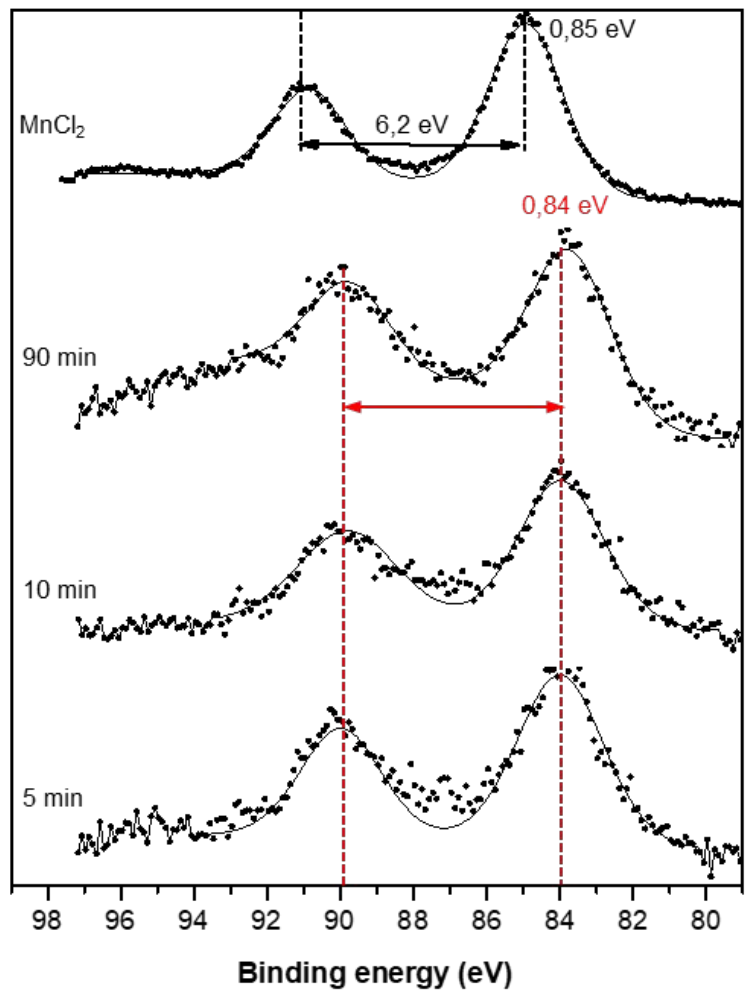

Figure S6. XPS core peaks spectra of Mn 3s of the titania spheres after 5, 10 or 90 min microwave radiation at $150{ }^{\circ} \mathrm{C}$ in the presence of $\mathrm{MnCl}_{2}$.

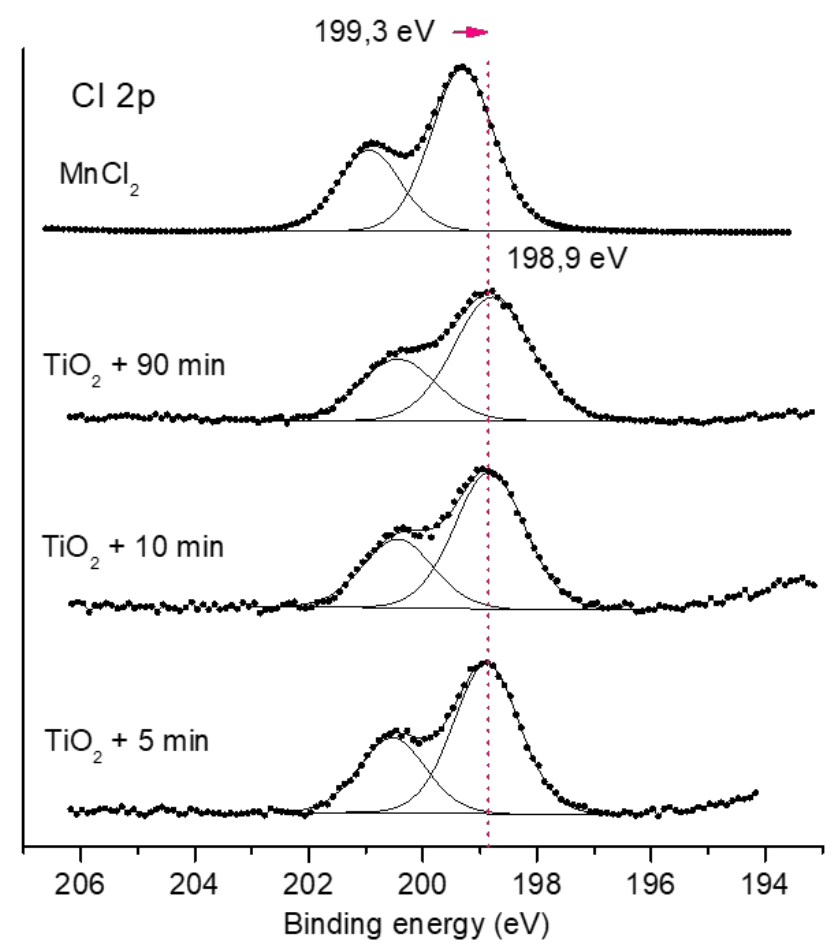


Figure S7. XPS core spectra of $\mathrm{Cl} 2 \mathrm{p}$ of the titania spheres after 5,10 or $90 \mathrm{~min}$ microwave radiation at $150{ }^{\circ} \mathrm{C}$ in the presence of $\mathrm{MnCl}_{2}$. 